\title{
LO MARGINAL Y LO PÚBLICO EN ORIHUELA A TRAVÉS DE LA ACCCIÓN PUNITIVA DEL JUSTICIA CRIMINAL. 1416-1458
}

Juan Antonio Barrio Barrio

Universidad de Alicante

El objetivo del presente trabajo es realizar una tipificación de la actuación punitiva del justicia criminal de Orihuela durante la primera mitad del siglo XV, utilizando como principal fuente de información los libros de multas conservados en el Archivo del reino de Valencia y las actas Municipales del período estudiado, junto a documentación de la Cancillería Real, situando estas actuaciones en el contexto general del reino de Valencia en el período estudiado.

\section{EL JUSTICIA CRIMINAL COMO AGENTE PUNITIVO URBANO}

En el reino de Valencia los justicias locales representaban, en nombre del rey, la justicia ordinaria, teniendo jurisdicción en primera instancia sobre los delitos civiles y criminales que se cometiesen en la localidad donde ejercian la representación judicial. Desempeñaban, por tanto, el ejercicio ordinario local del mero y mixto imperio, ejecutando su autoridad y competencias habitualmente en primera instancia ${ }^{(1)}$.

En la villa de Orihuela, como en otros municipios valencianos, existía a principios del siglo XIV un único justicia, que conocía las causas criminales y las civiles que superasen determinada cantidad pecuniaria. Pero, como en Valencia, la alta magistratura tuvo una corta duración ${ }^{(2)}$. En la capital del reino Jaime II en 1321 "ordena la escisión del Justiciazgo valenciano en dos nuevas magistraturas ${ }^{\star(3)}$. En Orihuela, en 1336, la reina Leonor, en nombre del infante Don Fernando, ordenó la elección el día de Navidad de dos justicias, uno para las causas criminales y otro para las civiles ${ }^{(4)}$. La curia del justicia criminal la integraban el propio justicia, su asesor, su lugarteniente, el escribano y los lugartenientes del justicia en los aldeas de realengo dependientes de la villa de Orihuela. 
El Justicia criminal de Orihuela entre sus atribuciones policiales o penales tenía que mantener el orden público en la villa, para lo cual contaba con una guardia, debiendo organizar los servicios de vigilancia nocturna (guaytas). Aunque según el modelo de justicia medieval valenciana tenía que actuar a instancia de parte, en la represión del delito contaba con competencias para prender 0 castigar a los malhechores que sorpren-diese ${ }^{(5)}$, especialmente en lo referente a portar armas prohibidas ${ }^{(6)}$. La forma habitual utilizada por el justicia criminal era la multa o composición pecuniaria fijada sobre el infractor, siempre y cuando éste se aviniese a pagarla, ya que de lo contrario podía embargar el cuerpo del delito, como era el caso de aquellos que habían sido sorprendidos portando armas prohibidas, vendiéndose en pública subasta el objeto confiscado por el corredor público.

En la composición la cantidad solía ser inferior a la pena fijada en la ordenanza y con esta actuación rápida y expeditiva el justicia recaudaba íntegramente el importe de la multa, en beneficio propio, sin tener que recurrir al reparto en tercias fijado en la legislación valenciana y el infractor se beneficiaba abonando una cantidad substancialmente inferior a la fijada en la ley ${ }^{(7)}$.

Este procedimiento era también utilizado por el Justicia criminal para fijar composiciones pecuniarias ilegales, por ejemplo sobre la práctica de determinados juegos como ha señalado Pérez García para Valencia, dándose una práctica similar para Orihuela, con las donaciones "generosas, voluntarias o acostumbradas", que realizaban algunos jugadores habituales en la tahurería al justicia criminal para poder seguir realizando sus actividades. En 1443 Pere Rodrigo, "taulager e arrendador del taulell...li volgut donar de sa plena volentat hun real", o el caso de Bertomeu Gomez que por jugar con un judío " $/ i$ dona graciosament per fer li plaer hun rea ${ }^{\prime(8)}$. En ocasiones la cifra podía ser muy elevada como los doscientos sueldos que pagaron en 1445 Joan Martínez y Alfonso Gonzalbez que tenían mesas de juego en la tahurería y "se composaron" con el Justicia criminal ${ }^{(9)}$.

El justicia criminal debía velar por que se cumpliesen las ordenanzas municipales sobre orden público, especialmente durante el toque de queda, después de haber sonado la campana de la hora del seny del lladre. A partir de este momento no se podía circular por la villa sin luz, con armas prohibidas, tener abiertos los hostales, etc. Se observa que en su cumplimiento los magistrados seguían la práctica habitual de las composiciones con los infractores ${ }^{(10)}$. La obligación de desplazarse con luz después del toque de queda era habitual en el resto de localidades valencianas como la capital del reino ${ }^{(11)}$, Cocentaina ${ }^{(12)}$, Xixona ${ }^{(13)}$, etc.

El estudio de los libros de multas del justicia criminal oriolano nos permite comprobar que es posible realizar una tipificación de las esferas delictivas que entraban dentro del campo prioritario de su actuación punitiva y recaudatoria, como un medio de represión del delito sin garantías procesales y que busca la proliferación de las penas pecuniarias ${ }^{(14)}$, como forma de obtener ingresos, legales e ilegales, para 
la curia y de los que al finalizar el ejercicio el oficial obtendría su sueldo, cifrado en mil sueldos valencianos, ya que se nutría de los ingresos procedentes de las multas impuestas.

La esfera de actuación punitiva del justicia se circunscribe a una serie de infracciones como las multas y licencias sobre armas prohibidas, el juego legal e ilegal, la actuación sobre hostaleros y la prostitución y a unos espacios delictivos habituales como el lupanar, los hostales y las mesas de juego, amén de zonas como la lonja, el mercado, las calles estrechas y sinuosas u otros recintos donde el oficial municipal y sus guardias tenían que estar atentos a la presencia de cualquier arma ilícita, que desenvainada o no podía provocar peleas, tumultos, refriegas callejeras y en ocasiones derramamiento de sangre. La regulación, la intervención y el control especialmente de la prostitución, el juego y las armas prohibidas permitía al magistrado municipal recaudar al año buena parte de los ingresos de su tribinal en concepto de multas, de los que se obtenía entre otros el salario del propio oficial y en segundo término cumplir su pretendida función represora de la delincuencia. Utilizando una expresión de Pérez García "la composición se podía convertir fácilmente en componenda"(15).

En este escenario el justicia cumplía ante sus ciudadanos con una de sus principales misiones, la represión del delito, aunque sería mas correcto hablar de la adecuada regulación de los actos prohibidos en unas coordenadas y en unos espacios delimitados, como la prostitución, que estaba permitida sólo en el lupanar y bajo unas circunstancias muy precisas, como veremos, o el juego que debía ser practicado en la tahurería y también bajo unas reglas muy minuciosas en cuanto a modalidades de juego, dados o naipes, apuestas permitidas, etc. Por tanto, el deber del justicia no era impedir que se realizasen una serie de actividades consideradas por los moralistas y las autoridades como perniciosas, sino que se ajustasen a unas reglas fijadas de antemano y que se recogen en las ordenanzas municipales y en las leyes.

\section{EL CONTROL SOBRE LAS ARMAS PROHIBIDAS}

Los fueros prohibian portar cierto tipo de armas y aunque en un primer momento se impedía llevar un puñal mayor de un palmo de alna ${ }^{(16)}$, más tarde la medida fue ampliada a un palmo y medio. Correspondía al justicia el control de las armas prohibidas, confiscándolas y otorgando licencias, facultad que sólo competía al rey y al justicia criminal, quien podía concederla a sus subordinados, a los que le acompañaban en la guardia diurna y nocturna, a los escuderos o comensales de los oficiales reales, a los arrendadores o colectores de imposiciones y a sus oficiales, guardas y servidores. También a cualquier persona a discreción del justicia, vigilando que no participase en peleas intencionadas o concertadas, ya que su uso correcto sólo se permitía en defensa propia ante una acción imprevista. Cualquier actuación ilícita suponía la inmediata confiscación de las armas, 
correspondiendo al justicia su custodia ${ }^{(17)}$. Hay que señalar que Alfonso $\checkmark$ recordaba en 1456 al gobernador de Orihuela que dichas licencias eran concedidas por el justicia criminal y por tanto, no eran de su competencia, debiendo respetar esa provisión ${ }^{(18)}$.

El justicia criminal de Orihuela multaba por portar todo tipo de armas ofensivas y defensivas: puñales, lanzas, espadas, escudos, etc $^{(19)}$. Como hemos visto el oficial tenía facultad para conceder a su arbitrio licencia para portar armas prohibidas, como la que otorgó en 1445 a Joan de Sevilla para que pueda llevar espada y escudo por 4 sueldos. En los años 1436, 1443 y 1445 el importe de las sanciones sobre armas representan aproximadamente una cuarta parte sobre el total de multas impuestas por el Justicia criminal.

El importe de las composiciones osciló desde el sueldo que pago un tal Almarcha en 1443 por un puñal, hasta los treinta sueldos que abonó Joan López por una espada y un escudo en 1436. Las cantidades no eran muy elevadas y la importancia de las cifras recaudadas anualmente se explica por el número de actuaciones en este terreno con treinta y siete intervenciones en 1443 y 1445 que supusieron más del 30 $\%$ de las acciones punitivas incoadas por el magistrado en dichos ejercicios.

\section{EL JUEGO Y SUS DERIVACIONES PUNITIVAS}

En los estudios sobre el juego en la Edad Media se han recogido una variada gama de actividades lúdicas y de ocio practicadas por el hombre medieval en sus horas libres, que iban desde la ballesta, a la pelota, los dardos, los bolos, el ajedrez ${ }^{(20)}$, las cañas ${ }^{(21)}$, etc.

Pero en el mundo de la marginación, la violencia y la delincuencia se practican otros juegos considerados menos dignos por los moralistas y las autoridades: los naipes y los dados eran los preferidos. Para su práctica existía un marco legal y otro ilegal. EI primero se desarrollaba en la tahurería o casa de juego autorizada, el segundo en las tabernas, los hostales, las casas de los particulares, etc., lugares donde las autoridades municipales podían actuar en su represión e imponer las multas pertinentes.

Los dados y naipes, juegos de mesa, son los más practicados por los regnícolas valencianos, y como en otros lugares, sobre ellos recaen continuamente las prohibiciones de las autoridades locales y las amenazas de los predicadores, que en sus sermones advertían contra los efectos perniciosos de la pasión por estos juegos ${ }^{(22)}$. Es el caso de San Vicente Ferrer que atacó el juego como un gran mal de la sociedad valenciana, sobre todo el de dados, que "és molt malvat pecat contra Déu...e en aquest joch se cometen molt mals" y provocaba en los jugadores mayores perjuicios como el robo, el préstamo, la blasfemia, o el incumplimiento de los deberes a los que estaban obligados los cristianos en las festividades mayores ${ }^{(23)}$. 
El juego de naipes o cartas procedía de la India y su introducción en el reino de Valencia data del siglo $\mathrm{XIV}^{(24)}$, siendo prohibida su práctica ya tiempos del rey Jaime $I I^{(25)}$. Pero su difusión y éxito fue rapidísima y total hasta el último rincón del reino, alcanzando en Valencia la fabricación de naipes un notable desarrollo en el siglo $X V^{(26)}$. Tanto los naipes como los dados fueron prohibidos por las autoridades para evitar altercados y la ausencia de los trabajadores en sus obligaciones diarias, ya que en torno al juego se mueve un submundo muy difícil de controlar por el poder público. Las prohibiciones sobre determinados tipos de juegos, son conocidas en el reino de Valencia ya en época de Jaime II, en torno a $1320^{(27)}$. En Orihuela durante el reinado de Alfonso $V$ se promulgaron ordenanzas específicas sobre la prohibición de determinados juegos.

Para regular los juegos de dados y naipes la posición del municipio basculó entre las prohibiciones totales y la posibilidad de permitirlos bajo determinadas condiciones en la tahurería de la villa. Lo normal era el enfrentamiento entre dos posiciones, la de los vecinos y forasteros que querian jugar con total libertad por calles, hostales, casas particulares y las plazas de la villa y el deseo de las autoridades municipales de eliminar este juego incontrolado centralizándolo en la tahurería ${ }^{(28)}$, lo que les permitía arrendarla y obtener unos beneficios económicos. En 1417 los munícipes hubieron de prohibir expresamente la práctica del juego en la lonja ya que "...per lo dit joch molts dexen de fer ses faenes..."(29).

El incumplimiento de las ordenanzas municipales sobre el juego llevaba aparejada una sanción pecuniaria legal, que en Orihuela solía ser de sesenta sueldos. Esta suma se distribuía en tres partes, destinadas al acusador, al justicia de la villa en nombre del rey y a los jurados en nombre del Conse/ $/^{(30)}$, aunque en la práctica el Justicia criminal se componía, tanto con los jugadores como con los que regentaban mesas de juego, por cantidades muy inferiores. Tales prohibiciones no pretendían la total erradicación del juego, sino su regulación evitando la práctica descontrolada en la vía pública fuera de la tahurería, local destinado al juego, que era una renta real cedida al municipio oriolano desde finales del siglo XIII para las obras de las murallas $^{(31)}$, de ahí, por tanto, el interés por controlar el juego y no dejar escapar sus beneficios económicos. La tahurería se arrendaba anualmente en subasta pública ${ }^{(32)}$. En Concentaina en una ordenanza de 1269 la multa por jugar a dados también estaba fijada en 60 sueldos ${ }^{(33)}$.

Sancho IV de Castilla concedió en 1282 al concejo de Orihuela las tahurerías o casas de juego de la villa por tiempo de diez años ${ }^{(34)}$, y en 1285 realizó una definitiva concesión a perpetuidad. Posteriormente, ya bajo administración catalano-aragonesa Jaime II concedió en 1296 por un tiempo sujeto a voluntad real esas rentas, siendo poco después las casas de juego suprimidas en el contexto moralizante de la época. Un intento de las autoridades municipales en 1307 por recuperar la tahurería resultó infructuoso por la negativa regia, a pesar de la advertencia de los munícipes de que las prohibiciones no habían 
menguado la pasión por el juego de los oriolanos y la necesidad que tenía el municipio de recaudar esos fondos. En 1325 el Consell de la villa volvió a obtener las rentas de la tahurería, pero al año siguiente el rey redujo su tiempo de vigencia a un sexenio ${ }^{(35)}$. Tras el período en que Orihuela estuvo sometida al señorío del infante don Fernando, retornó al patrimonio real en 1364, año en que Pedro IV confirmó el privilegio que Sancho IV había concedido en $1285^{(36)}$. Juan I renovó la confirmación realizada por su padre en 1380 y $1388^{(37)}$, mientras que en el siglo XV correspondió a Alfonso $V$ su ratificación ${ }^{(38)}$.

Durante el siglo XV el Consell solía arrendar en subasta pública la tahurería, cuyo ámbito abarcaba la huerta y el término de la localidad, excepto el lugar de Guardamar, para lo que ordenaba previamente que se redactasen unos capítulos ${ }^{(39)}$. Al menos desde 1421 tenemos constancia de que la tahurería se podía ubicar fuera de los muros de la villa. En los capítulos del arrendamiento de 1453 aparece como un requisito su establecimiento fuera de los muros de la ciudad.

"...lo qual taullell tingue e haia a star fora lo mur de la dita ciutat...lo qual arrendador no puxa en alguna manera tenir taullell dins la dita ciutat... ${ }^{(40):}$

Para el estudio del arrendamiento de la tahurería por el Consell de la villa contamos con los capítulos de los años 1401, 1403, 1410, 1419,1421 y 1453 que regulaban las modalidades de juego permitidas, las cantidades máximas que se podían apostar, las condiciones en que los jugadores podían recibir prestamos, etc ${ }^{(41)}$.

1. Nadie podía tener mesa de juego en su casa ni en otro lugar, para jugar al juego de dados de la gresca, uno de los más practicados, ni a badalassa (desde 1453), ni prestar dineros para jugar, sólo el arrendatario de la tahurería, o a quienes éste concediese licencia bajo pena de sesenta sueldos ${ }^{(42)}$.

2. Nadie podía jugar a gresca ni rifa ni otro juego de dados en un lugar que no fuese la tahurería, so pena de sesenta sueldos o diez días en la prisión de la villa - a partir del año 1410 y que aumentaron a sesenta días en 1453 -, excepto los hòmens honrrats que en sus casas o donde quisiesen podrían jugar a cualquier juego. En la prohibición no se comprendían ni los juegos de taules, a los que podría jugar cualquiera persona, ni los que rifaran carne en las carnicerías, en contra de lo que sucedía en Valencia donde las rifas de carniceros y panaderos estaban prohibidas $^{(43)}$. Aunque en febrero de 1435 el Consell prohibio rifar cabritos.

Item lo dit consell ordena que negunes persones no puxen rifar cabrits neguns e aço sots pena de sexanta solidos...(44).

3. El comprador de la tahurería no podía prestar dineros sobre obligaciones, cartas de deudas, fianzas, posesiones, prendas de ganado, etc., sólo sobre prendas propias del jugador. Si el arrendatario 
realizaba un préstamo ilegal el deudor no quedaba obligado a pagar la deuda.

4. Quien jugase en el taulell del rey sobre prenda que no fuese suya y se le exigiese cumplimiento de la misma, debía pagar el precio que recibiera en el juego por dicha prenda, so pena de pasar diez días en la cárcel, veinte desde 1410 y desde 1453 a discreción del dueño de la prenda impagada.

5. El que jugase en el taulell de la tahurería no debería pagar ningún dinero que haya jugado o perdido a tantos y sólo debía pagar el dinero que le hayan prestado en la forma prescrita.

6. Si el comprador de la tahurería consintiere que alguien jugara a tantos o prestara dinero de otra forma que la prescrita, cada vez que lo hiciese fuese multado con sesenta sueldos ${ }^{(45)}$.

7. Los bienes de los que hubiesen jugado en la tahurería no podrán ser vendidos por lo que adeudasen, solamente las prendas que hubiesen depositado en poder del comprador de la tahurería y por la cantidad que hubiesen pedido prestada en el taulell.

8. El Consell se reservaba la facultad de modificar y mejorar los capítulos del arrendamiento.

9. El arrendatario de la casa de juego podía prestar dineros a cualquier forastero que acudiese a la villa y a sus mozos o mensajeros en el taulell sobre prendas de ganado, ropas o cualquier bien que portasen y que fuesen de su propiedad. El Consell quedaba libre de toda evicción.

10. El arrendamiento duraba un año, y comprendía desde el día 1 de enero hasta el 31 de diciembre. El pago del importe se realizaría en cuatro partes, cada tres meses y el arrendatario daría fianzas a voluntad de los jurados.

11. Cuando se celebraba la feria algunas personas traían mesas de juego para jugar a los dados y cobraban taulatge, lo que perjudicaba los intereses del Consell, por lo que estableció la prohibición de esa práctica licita solamente al arrendatario.

12. El último capítulo establecia la modalidad de pago, fijada en cuatro partes, y las garantías pecuniarias que debía aportar el arrendatario según el criterio fijado por los jurados de la localidad.

En el arrendamiento de 1453 aparecen incluidos unos capítulos nuevos, como la prohibición en el juego de renegar y blasfemar contra Dios y los Santos, sobre cuya observancia debía velar el justicia criminal fijando la pena pertinente según lo estipulado en fueros. También se establecía la obligación del arrendatario de denunciar a todos los que blasfemasen bajo la pena de sesenta sueldos y la de pagar una cantidad suplementaria de cinco florines que las autoridades municipales destinarían para el juego de la carrera de caballos y el de ballesta.

El contrato de 1453 finalizaba con dos capítulos muy interesantes. En el primero se reconocía que en la calle que iba de la plaza hasta la casa de Pere de Rius se había permitido el juego y los vendedores que tenían tiendas habían protestado por las molestias que sufrían en sus obradores al no poder vender sus productos, por la 
"turbaçio e empaig" que les producian los jugadores. Atendiendo a estas protestas el Consell prohibió jugar en dicha calle en "retaules ni a portes de alguns obradors" y en aquella que iba de la plaza hasta el puente del "mercet", a ningún juego de "taules", ni de naipes ni dados, bajo pena de sesenta sueldos. Esta prohibición no afectaba a los hombres honrados según lo dispuesto en el segundo capítulo del arrendamiento. No sabemos si tal medida estuvo en relación con una disposición novedosa de dicho año, que regulaba el establecimiento de la tahurería fuera de los muros de la ciudad.

El último capítulo contradecía en parte el anterior, ya que rezaba que según disposición del Consell ninguna persona de cualquier ley "condiçio o estament sia per honrrada que sia no puxa jugar a nengu joch de daus taules ne naipes sens voluntat del arrendador", que podía conceder el pertinente permiso a cambio de cobrar el correspondiente derecho de taulatge. También se prohibía rifar "torrons" sin el consentimiento del arrendatario ${ }^{(46)}$.

El juego fue controlado y regulado por el Consell en el período estudiado, mediante ordenanzas municipales, las órdenes emitidas sobre los oficiales municipales y los capítulos del arrendamiento de la tahurería, prohibiendo que los vecinos de la villa pudiesen practicar determinados juegos, especialmente los dados, actividad que llego a estar totalmente vedada. El juego de dados de la gresca, como sucedía en Valencia ${ }^{(47)}$, era uno de los más populares y practicados y sobre él recayeron las más duras prohibiciones, quedando sólo permitido en la tahurería. En Cocentaina una ordenanza de 1269 prohibía terminantemente, de día y de noche, jugar a cualquier juego de dados $^{(48)}$.

En 1416, el Consell, ante el incumplimiento de las medidas aprobadas en años anteriores, recordaba la prohibición expresa de jugar al juego de gresca y a todos los juegos de dados.

"ftem, com gran temps ha pasat fos vedat lo joch de la grescha e tots los jochs de daus e altres. E en apres en l'any proppasat fos vedat per lo dit Consell que en la dita vila e sos térmens fosen jugats tots jochs de taules, e les gents sien tant gitats a jugar los dits jochs, e en special al joch que dien de la vella, en tal forma que es una gran destrucçió de moltes gents de la dita vila" ${ }^{(49)}$.

En los juegos lícitos, se llegaba a regular la cantidad máxima que se podía apostar por envite, así en el juego de la bufa sólo se permitía una apuesta ordinaria de un dinero en cada partida sin posibilidad de envite y en el de trenta taules la apuesta permitida era de tres sueldos con posibilidad de un envite y respuesta ${ }^{(50)}$. También se prohibía que en el alquiler de la mesa para jugar a la bufa se cobrase más de un dinero por el tiempo que durase el juego ${ }^{(51)}$.

En 1418 Joan Ferrer, asesor del justicia criminal, recordó en una reunión del Consell la ordenanza que prohibía jugar a los dados y a la gresca, ya que en la villa seguía practicándose, por lo que el 
lugarteniente del justicia detuvo a dos sarracenos ${ }^{(52)}$. Tres años después el consistorio prohibió jugar al juego de la bufa, a la vez que reiteraba su prohibición sobre el juego de la vella y los juegos de naipes ${ }^{(53)}$, quedando exentos los hombres honrados ${ }^{(54)}$. Si bien, dos años después el consistorio prohibió terminantemente los juegos de dados 0 naipes, quedando vedados para todos los vecinos, sin ningún tipo de exclusión por la categoría social; permitiendose sólo el juego que se hacía de treinta taules. La ordenanza se promulgaba de forma contundente ante los males que habían causado los juegos de dados y naipes en la villa, ya que a pesar de las prohibiciones promulgadas los justicias criminales concedían licencias para poder jugar. Quien vulnerase la medida sería multado con una pena de diez maravedíes de oro, y quien no pudiese pagaría la multa con el cumplimiento de una condena de sesenta días en la prisión común de la villa. La prohibición comprendía a todos los que consintiesen la práctica de dichos juegos en su casa y en caso de que el justicia criminal no ejecutase las penas ordenadas ni los jurados instasen a la ejecución de las penas, el gobernador del territorio o su lugarteniente podría ejecutarlas $^{(55)}$.

En 1435 las autoridades municipales prohibieron que durante los quince días que duraba la feria nadie jugara con dados ${ }^{(56)}$. Cinco años después como "el taulell se es levat e tolt de la dita ciutat e moltes persones axi homens honrrats com altres juguen a joch de daus" el Consell prohibió a todos los vecinos, sin exclusión de clase social, los juegos de dados excepto el de trenta taules y sólo autorizaba a los hòmens de be a jugar a las cartas ${ }^{(57)}$. La última noticia recogida es de 1446 cuando el Consell ante el conocimiento de la existencia de casas de juego ilegales, tuvo que recordar que sólo se podía jugar en la tahurería a los oficiales municipales para su adecuado cumplimiento, indicándoles que los jugadores sorprendidos en establecimiento ilegales abonarían el taulatge correspondiente a los arrendatarios de la tahurería de Orihuela ${ }^{(58)}$.

\section{MULTAS POR TENER EL HOSTAL ABIERTO}

El justicia criminal debía velar por que se cumpliesen las ordenanzas municipales sobre orden público, especialmente durante el toque de queda, después de haber sonado la campana de la hora del seny del lladre. A partir de ese momento no se podía circular por la villa con armas prohibidas, tener abiertos los hostales, etc. Se observa que en el cumplimiento de su obligación el justicia criminal y su lugarteniente seguían la practica habitual de las composiciones con los infractores ${ }^{(59)}$. Los hostaleros fueron multados por el Justicia criminal durante el período estudiado sobre todo por mantener el hostal abierto tras el toque de queda y por permitir en su establecimiento la práctica de juegos ilegales. 


\section{LICENCIA PARA EJERCER LA PROSTITUCIÓN EN EL BURDEL}

La prostitución urbana regulada en la Baja Media hay que situarla en el contexto de la fuerte intervención municipal de los siglos XIV y XV. Por ello uno de los fenómenos más destacados al hablar de la prostitución es su institucionalización, su "legalización", el establecimiento de un marco espacial y legal para poder llevarla a cabo. Las autoridades municipales se esforzaron por regular el ejercicio de esta actividad, dentro de unos cauces que eran considerados permisivos.

El marco legal de la prostitución tenía un espacio y un escenario definido: el burdel, también conocido en diversas localidades francesas como maison lupanarde, bon hostel, bonne carrière, Château-Gaillard, maison de la ville, maison commune, maison des filletes ${ }^{(60)}$. En este lugar y bajo el control de las autoridades municipales las "malas mujeres" podian ejercer la prostitución. Existía, por tanto, una permisividad legal mediatizada por una serie de condiciones concretas. La sociedad europea en general y la valenciana en particular proyectaron una permisividad social, moral y religiosa sobre el ejercicio de la prostitución. Se entendia como un mal menor que debía tolerarse, para evitar males mayores, buscando "proteger el orden sexual y la moral pública" ${ }^{\prime 61)}$.

Conocemos el burdel de Valencia desde principios del siglo XIV cuando Jaime II ordenó en 1325 la ubicación de las prostitutas en dicho lugar para ejercer su oficio previa licencia del Justicia Criminal, prohibiéndolo en las calles de la ciudad, siendo adscritas a un hostalero que se comprometía a velar por ellas y era responsable de su conducta ${ }^{(62)}$. Por tanto, en el burdel, que fue creado para eliminar la prostitución callejera, las autoridades podían controlar a las mujeres públicas que vivían dentro del recinto con el mayor aislamiento posible y a las que se les impedía salir de sus límites sin haber obtenido previamente la licencia del Justicia Criminal, ya que se cerraba por la noche y las prostitutas que habían obtenido licencia para salir quedaban obligadas a regresar a dormir en el lupanar antes del cierre del mismo ${ }^{(63)}$.

Para las mujeres públicas existian una serie de normas que debían cumplir: ejercer la prostitución sólo en el burdel, acceder al mismo sólo con el consentimiento de los oficiales municipales pertinentes $y$, en su caso, pagar la correspondiente licencia. Para los potenciales clientes también se establecían una serie de normas: "el acceso al burdel público era libre para los ciudadanos y los extranjeros cristianos; en cambio, quedaba prohibido a judíos y musulmanes al margen de cual fuera su estado civil o su condición social"(64). En Dijon el acceso a los prostíbulos públicos estaba prohibido a los casados y a los clérigos, pero estas normas no se cumplían. Desde un punto de vista moral la sociedad veía incluso con buenos ojos la asistencia regular de los jóvenes solteros al burdel, como forma aceptada para solazarse sin levantar recelos entre los hombres casados y el resto de la sociedad ${ }^{(65)}$.

En Orihuela, como sucedía en la ciudad de Valencia, una de las funciones del tribunal del justicia criminal era cobrar a las prostitutas, 
que se instalaban en el burdel de la villa, el canon correspondiente que debían pagar para legalizar su situación fijado habitualmente en tres sueldos ${ }^{(66)}$.

"Item, rebé més de Johana, amiga de Johan de les Penyes, fembra mundària, per ço com cascuna dona mundària és tenguda donar al justícia tres sous quant ve al borde/(67)."

"Item, rebé de la Navarra, fembra mundària, tres sous, per ço que era venguda novament al bordell e.s axí costuma e pràticha que cascuna fembra que novament ve paga al justícia tres sous ${ }^{(68)}$."

En 1402 Martín I recordaba la ordenanza municipal que prohibía en Orihuela a las mujeres publicas habitar en hospicios y hostales fuera del burdel y sólo se les permitía pasar un día o una noche, fijando su lugar de residencia en el lupanar, ya que los hostaleros de la villa incumplían la ordenanza y las atraían para animar el negocio. Por cuestiones de salud y moral públicas las prostitutas, descritas en la documentación como morbo pestífero, se equiparaban a la maligna enfermedad, debiendo permanecer recluidas y alejadas del resto de las mujeres para evitar todo tipo de contagio social, siendo el justicia el encargado de hacer cumplir la ordenanza ${ }^{(69)}$. De nuevo en 1451 Alfonso $V$ se quejó al justicia de la ciudad de Orihuela porque toleraba que las prostitutas vivieran fuera del lupanar, en contra de lo estipulado en los fueros. Ante la protesta de Nicolau Orumbella, señor del dominio útil del citado lupanar, le ordenó que dichas prostitutas comiesen, residiesen, durmiesen, etc., en el burdel, bajo pena de cien maravedíes ${ }^{(70)}$.

En el período estudiado el burdel de Orihuela se encontraba extramuros, fuera de los muros del arrabal de la ciudad, lo que ocasionó graves problemas en 1456 cuando unos castellanos lo atacaron, intentando asesinar al justicia criminal y al lugarteniente del raval y llevándose consigo a las mujeres, lo que obligó al municipio a ordenar que se hiciese un muro con seis puertas delante del burdel para poder cerrarlo por la noche ${ }^{(71)}$. Este rapto de "sabinas" es una demostración siglos después del episodio mitológico, del "hambre demográfica" de los territorios fronterizos medievales. En este caso los raptores, posiblemente murcianos, empleaban un método expeditivo para poder abastecer de mujeres publicas los burdeles del territorio limítrofe castellano. Como vemos la famosa trata de blancas no es ni mucho menos un invento actual.

En Orihuela la terminología habitual en los libros de multas del Justicia para designar a las mujeres públicas es "fembra mundària" que entronca con la denominación habitual en tierras murcianas ${ }^{(72)}$ y desconocida para la ciudad de Valencia ${ }^{(73)}$. El término también aparece recogido en la documentación de Cancillería. "...feminas mundarias seu meretrices..." ${ }^{74)}$, y excepcionalmente se aplica la denominación de "bagassa", cuyo uso sí se conoce entre las clases populares de Valencia $^{(75)}$. 
El control de la prostitución por parte del justicia criminal tuvo una incidencia en las multas impuestas que se sitúa en torno al $15 \%$ de las actuaciones del magistrado y el $3^{\prime} 5 \%$ de las sanciones pecuniarias impuestas. La primera cifra muestra claramente la importancia que tuvo esta actividad en Orihuela en el meridiano del Cuatrocientos con quince casos en 1443 y diecisiete en 1445, mientras que el bajo porcentaje de las sanciones se explica porque se aplicaba una composición fija de 3 sueldos sobre las mujeres públicas que acudían al burdel.

\section{OTROS DELITOS}

En este último apartado queremos incluir todos aquellas actuaciones delictivas punidas por el Justicia criminal y que se salen de su marco habitual de intervención como las peleas, el fraude fiscal o la importación o venta ilegal de determinados productos como telas, trigo y vino así como los delitos sobre la propiedad ante el robo de productos diversos. Llaman la atención casos como la multa de 50 sueldos impuesta al carnicero Joan Martínez por desmentir a otro en presencia del justicia criminal o los 5 sueldos que tuvo que pagar el menestral Guillen por parlat descortes. También los 9 sueldos cobrados a la judería por la protección acostumbrada que recibían el viernes santo. En el terreno de los delitos sexuales destacar la sanción impuesta al maestro de leer y escribir Joan López por realizar actos deshonestos, o los 52 sueldos de multa sobre la criada de Joan Marí y su compañera ambas beates de la parroquia de San Jaume por realizar "adulterio" ambas con Joan Vicent, o los 10 sueldos impuestos a María por actuar como alcahueta de su hija, práctica habitual en tierras valencianas ${ }^{(76)}$. También fueron multados algunos vecinos por negarse a realizar la guardia nocturna o por abandonarla antes de tiempo. Aunque no debió ser frecuente hemos recogido dos casos de homicidio en los que sus autores fueron exculpados al llegar a una composición con el Justicia, con la intervención en ambos del Baile general. En 1443 Martí y Joan Aldeguer se compusieron por valor de trescientos treinta sueldos por la muerte de Joan d' Anyo. Dos años después Pere de Alarco, Miguel Córdoba y Jaume García en un caso similar se compusieron por valor de 275 sueldos por la muerte de un judío.

\section{A MODO DE CONCLUSIÓN}

A falta de un estudio, más completo y exhaustivo sobre la violencia urbana en la Gobernación de Orihuela y la represión de la misma, esta aproximación nos permite arrojar unas conclusiones previas.

Los datos obtenidos sobre todo de los libros de multas del Justicia criminal no son suficientes para analizar en todas sus vertientes los fenómenos violentos en las ciudades del sur del País Valenciano en la Baja Edad Media, pero nos pueden ofrecer una tipología de los delitos 
más habituales como llevar armas prohibidas, el juego, la prostitución, etc. y los mecanismos más frecuentemente empleados por el magistrado urbano para su control y regulación y la posibilidad de comparar estos datos con los presentados para otras localidades. En esta misma revista un artículo de Enric Guinot sobre la actividad del Justicia de Xixona, una pequeña localidad rural valenciana, muestra un panorama muy diferente al de Orihuela y al de grandes ciudades como Valencia.

Por otra parte y tras los recientes estudios realizados sobre la violencia y la actuación judicial en Valencia por Rafael Narbona, es necesario ampliar esta línea de investigación al resto de localidades del reino, debiendo establecer la adecuada comparación entre la tipología de los centros urbanos con los datos que afloren sobre las localidades rurales. Bajo esta perspectiva globalizadora hemos abordado este articulo como primer paso hacia un mayor conocimiento de lo marginal y lo público en el territorio de la Gobernación de Orihuela en el siglo XV. 



\section{NOTAS}

1. PÉREZ GARCíA, P. El Justicia criminal de Valencia (1479-1707). Una magistratura urbana valenciana ante la consolidación del Absolutismo. Valencia, 1991.

2. ROCA TRAVER, F. El Justicia de Valencia (1238-1321). Valencia, 1970.

3. PÉREZ GARCÍA, P. "Origen y configuración del una magistratura urbana de la Valencia foral: El Justicia Criminal", en Estudis, 13 (Valencia, 1987), págs. 21-73, pág. 39.

4. A(rchivo) H(istorico) N(acional). Códice 1368-B. Privilegia per Serenissimos Reges ciuitati Oriole concesa. ff. 94r-95r. 1336, mayo, 17.

5. Sobre la represión del delito en la Valencia bajomedieval vid. NARBONA VIZCAÍNO, R. Malhechores, violencia y justicia ciudadana en la Valencia bajomedieval (1360-1399). Valencia, 1990. PÉREZ GARCÍA, P. La comparsa de los malhechores. Valencia 1479-1518. Valencia, 1990.

6. Sobre el particular vid. PÉREZ GARCÍA, P. "Origen y configuración..."

7. Así en 1417 el justicia criminal se compuso con cuatro vecinos que jugaban a la vella a razón de tres sueldos cada uno, cuando la multa fijada un año antes era de sesenta sueldos. A(rchivo) R(eino) de V(alencia). A.R.V. Maestre Racional, 9584, Multas del Justicia criminal de Orihuela y su lugarteniente, año 1417, ff. 155r-156v.

8. A.R.V. Maestre Racional, reg. 7071. Multas del Justicia criminal de Orihuela y su lugarteniente de 1443.

9. A.R.V. Maestre Racional, 9588, Multas del Justicia Criminal de Orihuela y su Lochtinent, año 1445.

10. "Primerament rebé de Ferrando, ostaler del bordell, per composició feta entre aquell e lo dit justícia, per ço que li era encorregut en algunes penes per tenir ubert lo ostal tocada la campana, per com per crida feta per lo dit justícia fos encorregut per cascuna vegada en pena de cinch sous per quantes vegades que fos encorregut en la dita pena, feu la composicion sobre dita per quinze sous com de los als li.u fes gràcia." A.R.V. Maestre Racional, reg. 7071, Multas del justicia criminal de Orihuela y su lochtinent, año 1443, f. 11 r.

11. NARBONA VIZCAÍNO, R. Malhechores, violencia y justicia ciudadana...

12. PONSODA SANMARTÍN, J.J. El català i l'aragonés en els inicis del Regne de València segons el llibre de Cort de Justícia de Cocentaina (1269-1295), Alcoi, 1996, pág. 48. (1269, febrero, 4).

13. GUINOT, E. "Sobre l'activitat de la justícia a un menut poble valencià d'inicis del segle XV: Xixona (1413)", artículo publicado en esta misma revista.

14. PÉREZ GARCÍA, P. "Una reflexión en torno a la historia de la criminalidad", Violència i marginació en la sociedad medieval. Revista d'Història Medieval. Valencia, 1, 1990, págs. 11-37.

15. Sobre todo por el título y el contenido del epígrafe "La ¿represión? del juego ilícito en la Valencia tardomedieval. De la ténue frontera que separa la 
composición de la «componenda»", de su libro La comparsa de los malhechores...

16. En Cocentaina en 1296 no se podía llevar un cuchillo mayor de un palmo de "alna e de // ditz..." PONSODA SANMARTíN, J.J. El català i l'aragonés... pág. 47. (1269, enero, 11).

17. BARRIO BARRIO, J.A. El ejercicio del poder en un municipio medieval: Orihuela, 1308-1479. Alicante, 1993. (Tesis doctoral en microficha).

18. A.R.V. Real, reg. 57, f. 120v. (1456, febrero, 8).

19. Las armas blancas eran la más utilizada en las villas europeas en el período estudiado. GONTHIER, N. Cris de haine et rites d'unité. La violence dans les villes, XIII -XVP siècle, Brepols, 1992, págs. 113-115.

20. HINOJOSA MONTALVO, J. "El juego en tierras alicantinas durante la Baja Edad Media", Espai i temps d'oci a I'Història. XI Jornades d'Estudis Històrics Locals, Palma de Mallorca, 1993. págs. 395-407.

21. Item lo dit clavari dona e paga quatre diners per a hun joch de canyes que jugaren en lo raval... A.M.O. Contestador, n.․․ 1045. Libro de claveria año 1427. 22. Ibídem, pág. 402.

23. NARBONA VIZCAÍNO, R. Pueblo poder y sexo. Valencia medieval (1306-1420). Valencia, 1992, págs. 91-93.

24. HINOJOSA MONTALVO, J. "El juego en tierras alicantinas...", pág. 402.

25. PÉREZ GARCÍA, P. La comparsa de los malhechores..., pág. 88.

26. HINOJOSA MONTALVO, J. "El juego en tierras alicantinas...", pág. 402.

27. Vid. PÉREZ GARCÍA, P. La comparsa de los malhechores..., págs. 87-90, donde hace referencia $y$ detalla las principales interdicciones sobre determinados tipos de juego, dictadas por la corona desde Jaime II a Fernando el Católico, desde principios del siglo XIV hasta comienzos del siglo $\mathrm{XVI}$.

28. Ibídem, pág. 405.

29. A(rchivo) $M\left(\right.$ (unicipal) de $O$ (rihuela). Contestador, n. ${ }^{0}$ 16, f. $144 \mathrm{v} .1417$, septiembre, 4.

30. A.M.O. Contestador, n. -15 , ff. 194v-195r. (1416, marzo, 20).

31. En 1446 el Consell decidió destinar los ingresos por el arrendamiento de la tahurería para el muro del arrabal de la puerta de Elche. A.M.O. Contestador, n.․ 27 f. 8r. (1446, enero, 2).

32. HINOJOSA MONTALVO, J. "El juego en tierras alicantinas...", pág. 406.

33. PONSODA SANMARTÍN, J.J. El català i l'aragonés... pág. 47. (1269, enero, 11).

34. ESTAL, J.M. Documentos inéditos de Alfonso $X$ el sabio y del Infante, su hijo Don Sancho. Alicante, 1984. IV parte. Doc. n. 8. 1282, mayo, 20. págs. 119-121.

35. FERRER I MALLOL, M. ${ }^{-}$T., Organització $i$ defensa d'un territori fronterer. La Governació d'Oriola en el segle XIV. Barcelona, 1990, págs. 164-165. 
36. CABEZUELO PLIEGO, José Vicente. Documentación alicantina en el Archivo de la Corona de Aragón durante el reinado de Pedro IV el ceremonioso. 1355-1370. Memoria de licenciatura. Alicante, 1989. Doc. n. 41 . 1364, septiembre, 24. Id. La Guerra de los dos Pedros en las tierras alicantinas. Alicante, 1991. pág. 95.

37. A.H.N. Privilegia... ff. 195r-197v. (1380, octubre, 13). A(rchivo) de la C(orona) de A(ragón). $C$, reg. 1895, ff. 77v-79v. (1388, octubre, 13).

38. A(rchivo) $\mathrm{H}$ (istorico) N(acional). Privilegia... ff. 307r-308r. 1419, septiembre, 25. A.R.V. Real, reg. 393, f. 40 r-v. 1419, septiembre, 25.

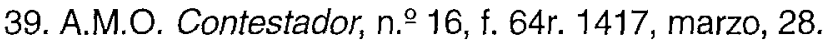

40. A.M.O. Contestador, n. 2277, f. 91r. Año 1453.

41. A.M.O. Contestador, n. .1034 , ff. 83r-85r. Capítulos del arrendamiento de la tahurería. Año 1401; n. 845, s/f. Año 1403; n. 1034, s/f. Año 1410. n. ${ }^{\circ}$ 1040, s/f. Año 1419; n. 909, s/f. Año 1421; n. 2277, ff. 91r-92r. Año 1453.

42. El importe de la multa lo recibirían el justicia criminal en nombre del rey, los jurados en nombre del Consell y el comprador de la tahurería.

43. PÉREZ GARCÍA, P. La comparsa de los malhechores..., pág. 92.

44. A.M.O. Contestador, n.․․ 21, f. 16. 1435, febrero, 13.

45. En este caso la multa se repartía entre el justicia criminal en nombre del rey, el Conselly el acusador en tres partes iguales.

46. A.M.O. Contestador, n. 2277, ff. 91r-92r. Año 1453.

47. PÉREZ GARCÍA, P. La comparsa de los malhechores..., págs. 92-93.

48. PONSODA SANMARTÍN, J.J. El català i l'aragonés... pág. 47. (1269, enero, 11).

49. A.M.O. Contestador, n. 15 , ff. 194v-195r. (1416, marzo, 20).

50. A.M.O. Contestador, n.o 15, f. 195r. 1416, marzo, 20.

51. A.M.O. Contestador, n.o 15, f. 195r. 1416, marzo, 20.

52. A.M.O. Contestador, n. 9 17, f. 92v. 1418, abril, 27.

53. A.M.O. Contestador, n. 19, f. 37r. 1421, enero, 29.

54. "Ara osats que.s fa hom a saber de part del honrrats justícia e jurats de la vila d'Oriola, a tot hom en general e a cascú en special, que algú no sia gosat jugar als jochs de la vella e de la bufa e als nayps, e açó en pena de $L X$ sous a cascú que contrafarà e per cascuna vegada... Emperò, que en açò no y sien entesos hòmens honrrats, los quals pusquen jugar a qualsevol joch que volrran..." A.M.O. Contestador, n.. 19, f. 37r. 1421, enero, 29.

55. A.M.O. Contestador, n. 19 , f. 164v. 1423, febrero, 3.

56. A.M.O. Contestador, n. 22, f. 131r. (1435, octubre, 26).

57. A.M.O. Contestador, n. $.24 \mathrm{ff} .21 \mathrm{v}-22 \mathrm{v}$. (1440, enero, 24).

58. A.M.O. Contestador, n. 927 f. 14r. (1446, enero, 30).

59. BARRIO BARRIO, J.A. El ejercicio del poder...

60. ROSSIAUD, J. La prostitución en el Medievo. Barcelona, Ariel, 1986. 
61. PERIS, M. ${ }^{\text {a }}$ C. "La prostitución valenciana en la segunda mitad del siglo XIV". Violència i marginació en la sociedad medieval. Revista d"Història Medieval, n.․․ Valencia, 1990, págs. 179-199.

62. GRAULLERA, V. "Los hostaleros del burdel de Valencia", Violència $i$ marginació en la sociedad medieval. Revista d'Història Medieval. Valencia, 1, 1990, págs. 201-213.

63. Ibídem, págs. 206 y 209.

64. PERIS, M..$^{\text {a }}$ C. "La prostitución valenciana...", págs. 184-185.

65. ROSSIAUD, J. La prostitución... págs. 56-57.

66. "Item, rebi de Leonor, amiga de Gomariz, fembra mundària, per ço com cascuna fembra mundària és tenguda pagar al lochtinent per la venguda al bordell... III sous." A.R.V. Maestre Racional, reg. 9588, Multas del justicia criminal de Orihuela y su lugarteniente, año 1445, f. 101r.

67. A.R.V. Maestre Racional, reg. 9588, Multas del justicia criminal de Orihuela y su lugarteniente, año 1445, f. 102 r.

68. A.R.V. Maestre Racional, reg. 7071, Multas del justicia criminal de Orihuela y su lugarteniente, año 1443, f. 11v.

69. A.C.A. $C$, reg. 2133 , f. 131 r-v. (1402, marzo, 8).

70. HINOJOSA MONTALVO, J. Textos para la historia de Alicante. Historia Medieval. Alicante, 1990. Doc. n.․214, págs. 410-411. 1451, septiembre, 16.

71. A.M.O. Contestador, n. 30 , f. 11v. (1456, diciembre, 27).

72. RUBIO GARCÍA, L. Vida licenciosa en la Murcia Bajomedieval. Murcia, 1991.

73. PERIS, M. a C. "La prostitución valenciana...", págs. 188-189.

74. HINOJOSA MONTALVO, J. Textos para la historia de Alicante... doc. $\mathrm{n}^{\circ}$ 214, págs. 410-411.

75. PERIS, M. a C. "La prostitución valenciana...", pág. 188.

76. Sobre la alcahuetería en Valencia vid. PERIS, M.a C. "La prostitución valenciana..." y GRAULLERA, V. "Los hostaleros del burdel de Valencia" 